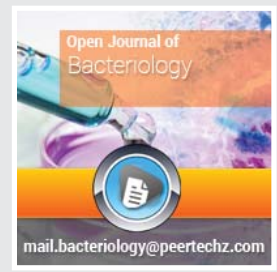

\title{
Open Journal of Bacteriology
}

\section{Shivangi, Amjad Beg, Swati Meena and Laxman S Meena*}

CSIR-Institute of Genomics and Integrative Biology, Council of Scientific and Industrial Research, Mall Road, Delhi, India

Dates: Received: 30 January, 2017; Accepted: 10 February, 2017; Published: 11 February, 2017

*Corresponding author: Laxman S Meena, Doctor, PhD, CSIR-Institute of Genomics and Integrative BiologyMall Road, Delhi-110007, India, Tel: 011-27666156; Fax No: 011-27667471; E-Mail: meena@igib.res.in; laxmansm72@yahoo.com

Keywords: M. tuberculosis; CXXC; CCM; Rv0526

https://www.peertechz.com

\section{Review Article \\ To Find out the Essentiality of Rv0526 Gene in Virulence of Mycobacterium tuberculosis by using In silico} Approaches

\section{Abbreviation}

M. tuberculosis: Mycobacterium tuberculosis; HIV: Human immunodeficiency virus; MDR: Multi drug resistant; XDR: Extensively drug resistant; TDR: Total drug resistant ; bp: Base pair; aa : amino acid; kD: kilo Dalton; Trx: Thioredoxin; ROS: Reactive oxygen species ; CXXC: Cystein XX Cystein ; CCM: Cytochrome c maturation

\section{Introduction}

Tuberculosis (TB) has emerged as a major world health problem, with almost one-third of the world population today infected with Mycobacterium tuberculosis $\mathrm{H}_{37} \mathrm{Rv}$ (M. tuberculosis) [1]. It is an infectious disease caused by the gram-positive bacilli $M$. tuberculosis [2]. This bacterium typically affects the lungs (pulmonary TB) but can also affect other sites (extrapulmonary TB). The disease is spread by airborne Mycobacterium particles. Overall, a relatively small proportion (5-15\%) of the estimated 2-3 billion people are infected with $M$. tuberculosis will develop TB disease during their lifetime. However, the probability of developing TB disease is much higher among people infected with HIV (Human immunodeficiency virus) [3]. Moreover, because of coinfection with HIV, nonadherence to the prescribed regimen, improper and incomplete treatment, and lack of proper diagnostic techniques have led to the emergence of multiple-drug-resistant strains. Years of investigation and genomic research find a collection of novel drugs which may help in the treatment of different varieties of TB such as MDR (multi drug resistant), XDR (extensively drug resistant) and TDR (total drug resistant). These new varieties of tuberculosis trigger us to move to form modern drugs [45]. This bacterium is an opportunistic pathogen of alveolar macrophages. Immunologically compromised person can get infected by this bacterium very sharply [6]. M. tuberculosis is an obligate aerobe, non-motile, slow growing ( 24-hour doubling time) and nonspore forming bacteria [7]. Due to its complex nature of cell wall macrophage cannot completely eradicate the bacterium and also this bacilli inhibit fusion between phagosome and lysosome [8]. In this article, we are dealing with specific features of Rv0526 by using in silico approaches. It is predicted that it may act as an important gene of thioredoxin protein family.

\section{In silico approaches of Rv0526}

In this study, we focused towards a gene named Rv0526 (651bp/ $216 \mathrm{aa)}$ having molecular weight of $23.218 \mathrm{kD}$ (from nucleotide sequence). It is possibly work as Trx like protein (thiol-disulfide interchange protein) which is similar to other 
well defined Trx like proteins of $M$. tuberculosis Rv1470, Rv1471, Rv1677 [9]. Trx proteins act as antioxidants by facilitating the reduction of other proteins by cysteine thiol-disulfide exchange. Trx is found in nearly all known organisms and is essential for life in mammals [10-11]. Trx plays a critical role in the regulation of cellular redox homeostasis. Trx is able to reduce a variety of target substrates and reactive oxygen species (ROS) through the cyclization of its active site dithiol to the oxidized disulphide Cys37-Cys40 (CXXC) [12]. Rv0526 is predicted to be secreted lipoproteins. It is located in the genomic region and predicted to be contains motif, which is required for cytochrome $c$ maturation (CCM). By using bioinformatic approach, we get different findings about this gene, which may help in getting more information about this gene to predict its functionality. Tuberculist amino acid sequence shows that Rv0526 gene containing the thioredoxin motif CXXC [13]. String database server shows the interaction of this protein with trxB, gltB, ahpC, ccsA, ccdA, hemL, dipZ, MT0550, MT2945 and MT 0547. It reveals that Rv0526 extremely interact with trxB, gltB and ahpC which prefigure that it may be involved a thioredoxin reductase [14]. As shown in Figure 1. The HMMTOP transmembrane topology prediction server predicts both the localization of helical transmembrane segments and the topology of transmembrane protein. By using HMMTOP server it is identified that gene Rv0526 forming a two transmembrane helices forming between 17-33 and 158-176 amino acid sequence, which localized in the membrane [15].

PSORT (Prediction of Protein Sorting Signal and Localization Sites in Amino Acid Sequence) analysis shows that Rv 0526 gene majorly resides in mitochondria which further predict that it is essentially involved in cytochrome $C$ maturation and electron transport chain as shown in Table 1 [16]. Lipo P tools which help in discriminating between lipoprotein signal peptides. Lipo P confirms that Rv0526 contains SpI: signal peptide (signal peptidase I) and SpII: lipoprotein signal peptide (signal peptidase II) as shown in Figure 2 [17]. Overall result prediction for Rv0526 in our study is summaries in Table 2.

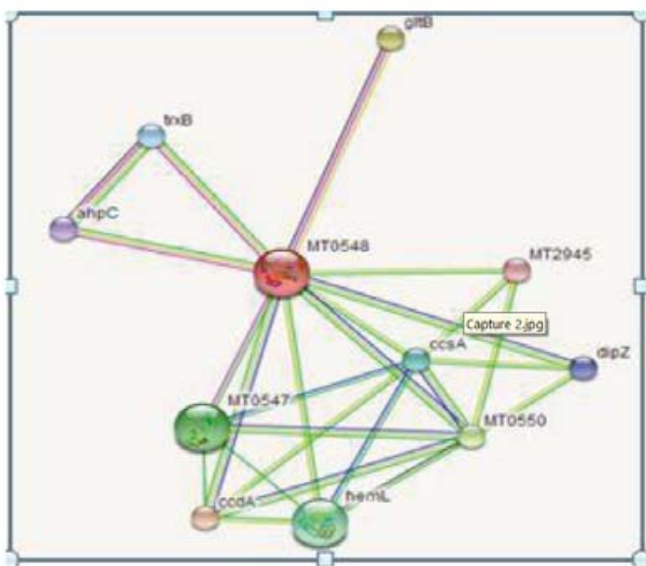

Figure 1: STRING database result which shows protein-protein interaction: A STRING database server, which is used for prediction of protein-protein interactions. The interactions include direct (physical) and indirect (functional) associations; the stem from computational prediction, from knowledge transfer between organisms, and from interactions aggregated from other (primary) databases.
Table 1: PSORT (Prediction of Protein Sorting Signal and Localization Sites in Amino Acid Sequence) tool.

\begin{tabular}{|c|c|}
\hline Localization Site & Percentage of Localization \\
\hline Mitochondrial & $47.8 \%$ \\
\hline Cytoplasmic & $17.4 \%$ \\
\hline Golgi & $13.0 \%$ \\
\hline Endoplasmic Reticulum & $13.0 \%$ \\
\hline Nuclear & $4.3 \%$ \\
\hline Vacuolar & $4.3 \%$ \\
\hline
\end{tabular}

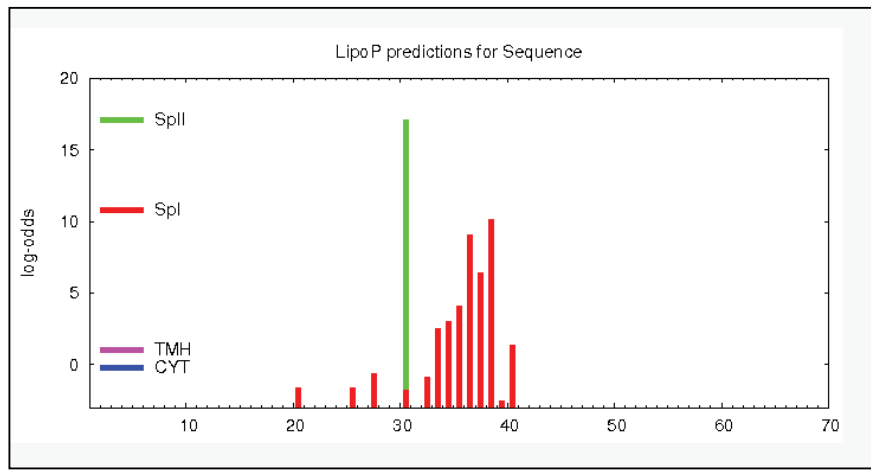

Figure 2: STRING database result which shows protein-protein interaction: A STRING database server, which is used for prediction of protein-protein interactions. The interactions include direct (physical) and indirect (functional) associations; the stem from computational prediction, from knowledge transfer between organisms, and from interactions aggregated from other (primary) databases.

Table 2: Overall result prediction for Rv0526

\begin{tabular}{|c|c|c|c|}
\hline S.No. & Used Tools & Function Prediction & Result \\
\hline 1 & STRING & $\begin{array}{r}\text { predicted protein-protein } \\
\text { interactions }\end{array}$ & $\begin{array}{r}\text { Rv0526 interact with trxB, gltB, } \\
\text { ahpC, ccsA, ccdA, hemL, dipZ, } \\
\text { MT0550, MT2945 and MT 0547 }\end{array}$ \\
\hline 2 & HMMTOP & $\begin{array}{r}\text { Predictions of } \\
\text { transmembrane helices and } \\
\text { topology of proteins }\end{array}$ & $\begin{array}{r}\text { 2 transmembrane helices forming } \\
\text { between 17-33 and 158-176 } \\
\text { amino acid sequence }\end{array}$ \\
\hline 3 & PSORT & $\begin{array}{r}\text { prediction of protein } \\
\text { localization sites } \\
\text { discriminating between }\end{array}$ & Localized in mitochondria \\
\hline 4 & LipoP & $\begin{array}{r}\text { lipoprotein signal peptides, } \\
\text { other signal peptides }\end{array}$ & Contain SP I and SP II \\
\hline
\end{tabular}

\section{Summary}

We can summarize that Rv0526 might be a Trx like protein, which is important for CCM. CCM is the significant component of an electron transport chain of aerobic respiration. Rv0526 containing CXXC motif that is responsible for the activity of Trx like proteins. It is also shows homology with Rv3673 which is proven to be act like a thioredoxin. Understanding of these specific features of Rv0526 gene conclude that this gene may act as an essential drug target. Mutation in the Cystein of this motif which is a part of Trx motif can play a significant role in killing the pathogenesis of mycobacterium. Further study required to understand the physiological and biochemical role of this gene to may develop antituberculosis drugs. 


\section{Acknowledgement}

The authors acknowledge the financial support from OLP1121 and GAP0092 of the Department of Science and Technology and Council of Scientific \& Industrial Research.

\section{References}

1. Meena LS, Dhakate SR, Sahare PD (2012) Elucidate of Mg2+ binding activity of Adenylate kinase from Mycobacterium tuberculosis H37Rv using fluorescence studies: International Union of Biochemistry and Molecular Biology 59: 429-36. Link: https://goo.gl/ISZmMw

2. Meena LS and Rajni (2010) Survival mechanisms of pathogenic Mycobacterium tuberculosis H37Rv: FEBS J 277: 2416-2427.Link: https://goo.gl/xOEyxy

3. Rajni and Meena LS (2010) Guanosine triphosphatases as novel therapeutic targets in tuberculosis: Int $\mathrm{J}$ Infect Dis 14: e682-e687. Link: https://goo.gl/GMbi90

4. Sharma SK and Mohan A (2006) Multidrug-resistant tuberculosis: a menace that threatens to destabilize tuberculosis control: Chest 130: 261-272. Link: https://goo.gl/Gcdu3w

5. Cole ST, Brosch R, Parkhill J, Garnier T, Churcher C et al. (1998) Deciphering the biology of Mycobacterium tuberculosis from the complete genome sequence: Nature 393: 537-544. Link: https://goo.gl/U5uaGK

6. Kumari P, and Meena LS (2014) Factors affecting susceptibility to Mycobacterium tuberculosis: a close view of immunological defence mechanism: Appl Biochem Biotechnol 174: 2663-2673. Link: https://goo.gl/Pctukb
7. Parish T, Stoker NG (1999) Mycobacteria bugs and bugbears two steps forward and one step back: Mol Biotechnol 13: 191-200. Link: https://goo.gl/s34Psl

8. Ratledge C (1976) The physiology of the Mycobacteria: Adv Microb Physiol. 13: 115-244. Link: https://goo.gl/2rP9Ej

9. Link: https://goo.gl/L1ljNQ

10. Holmgren A (1989) Thioredoxin and glutaredoxin systems: J Biol Chem 264 13963-6. Link: https://goo.gl/b7ZQOd

11. Nordberg J, Arner ES (2001) Reactive oxygen species, antioxidants, and the mammalian thioredoxin system: Free RadicBiol Med 31: 1287-312. Link: https://goo.gl/QYJbmS

12. Hall G, Bradshaw TD, Laughton CA, Stevens MF, Emsley J (2011) Structure of Mycobacterium tuberculosis thioredoxin in complex with quinol inhibitor PMX464: Protein Sci 210-5. Link: https://goo.gl/GbKHQd

13. Jennifer L S, Sae Woong Park, Bavesh D K, Thomas R loerger, et al. (2013) Perturbation of Cytochrome c Maturation Reveals Adaptability of the Respiratory Chain in Mycobacterium tuberculosis: American society for microbiology 400475-13. Link: https://goo.gl/yfEShj

14. Link: https://goo.gl/4A3UkD

15. Tusnady GE, Simon I (2001) HMMTOP transmembrane topology prediction server: Bioinformatics 17: 849-850. Link: https://goo.gl/L8qf2h

16. Link: https://goo.gl/RjrKy2

17. Rahman O, Cummings SP, Harrington DJ. Sutcliffe IC (2008) Prediction of lipoproteins and signal peptides in Gram negative bacteria 24: 2377-82 Link: https://goo.gl/7NFBro

Copyright: (c) 2017 Shivangi, et al. This is an open-access article distributed under the terms of the Creative Commons Attribution License, which permits unrestricted use, distribution, and r eproduction in any medium, provided the original author and source are credited. 